\title{
Minimal-medication approaches to treating schizophrenia ${ }^{\dagger}$
}

\section{Tim Calton \& Helen Spandler}

\begin{abstract}
SUMMARY
UK guidelines for treating people diagnosed with schizophrenia currently emphasise the primacy of antipsychotic medication, with or without psychosocially based interventions as circumstances dictate. We now see increasing calls, most notably from mental health service users, for the provision of 'whole-person-based', minimal-medication approaches to treating people with this diagnosis. This article is intended to locate the development of such approaches within the history of modern and pre-modern psychiatry and, in doing so, summarise the available evidence base that underpins their efficacy.
\end{abstract}

\section{DECLARATION OF INTEREST}

T.C. and H.S. are acting trustees of the Soteria Network UK.

Patient choice sits at the heart of current health policy in the UK (Department of Health 2003, 2008) and has been cited as a vital component of an evidencebased and patient-centred mental healthcare system (Fulford 1996; Department of Health 1999; Hope 2002). It could be argued that the concept of choice underpins informed consent to treatment, in that consent can perhaps only be said to be properly informed if a person appreciates that there are choices available to them (Grisso 1995; General Medical Council 1998). Conventional medical treatment of people diagnosed with schizophrenia continues to rely almost entirely on the (sometimes involuntary) use of antipsychotic medication. Nowhere is this more clearly adumbrated than in the National Institute for Health and Clinical Excellence (NICE) guidelines for treating schizophrenia (National Institute for Clinical Excellence 2002), which state that 'during an acute episode, antipsychotic drugs are necessary' (our italics), a mandate not extended to psychosocial interventions.

Our aim in this article is to consider the potential choices available to people diagnosed with schizophrenia who may be averse to an openly medical (and hence psychopharmacological) approach to treatment. We use the term 'potential' pointedly in this context because at present there is a dearth of substantive alternatives to orthodox biomedical treatment for people diagnosed with schizophrenia in the UK, a situation at odds with that in several other countries, most notably Germany, Finland, Sweden and the USA (Statsny 2007).

First, a note about terminology. 'Schizophrenia' is a thoroughly contested concept with many wellrehearsed arguments for and against its validity and utility. However, all of the studies conducted within the era of modern psychiatry, and cited in this article, use the term schizophrenia to describe the experiences of their participants. Although we might prefer the term 'psychosis', current mainstream psychiatric thought understands the two constructs as being qualitatively different. In the interests of exposition and communication we use the term schizophrenia throughout this article.

\section{The view from now}

At first glance, the case for the continuing primacy and necessity of antipsychotic medication in the treatment of people diagnosed with schizophrenia appears unassailable. There is a wealth of empirical evidence extending over many decades suggesting that antipsychotic medication produces significant improvements in schizophrenia symptoms (Davis 1976, 2003), prevents relapse (Hogarty 1974) and forestalls the problem of a long duration of untreated psychosis (Loebel 1992). However, there is some doubt about the consistency of these results and the nature and sustainability of longer-term outcomes (Bentall 2002; Moncrieff 2003). Over time, manifold problems emerge, such as non-concordance (Oehl 2000), treatment resistance (Kane 2007) and multifarious unpleasant, distressing and potentially life-threatening side-effects (Zarate 2001; Hennessy 2002). The second-generation or so-called atypical antipsychotics were introduced in an attempt to obviate some of the more distressing side-effects caused by the first-generation drugs. However, it is increasingly becoming apparent not only that they too engender negative side-effects, but that their putative increased efficacy has been overstated (Lieberman 2005; Jones 2006). Other research suggests that people diagnosed with schizophrenia may respond better to psychosocial treatment or a placebo than medication (Bola 2002, 2006) and that those who remove themselves from the psychiatric system, foregoing exposure to antipsychotic medication, may actually have greater
Tim Calton is a psychiatrist by training. An ex-user of mental health services, he critically explores this system using a variety of discursive, empirical and activism-based approaches. He is a special lecturer in the Department of Health Psychology at the University of Nottingham and Research Fellow at the Institute of Mental Health in Nottingham. Helen Spandler is a senior research fellow in the School of Social Work at the University of Central Lancashire. She has written on therapeutic communities and working with young people who self-harm.

Correspondence Dr Tim Calton, c/o Department of Health Psychology, Division of Psychiatry, A Floor, South Block, Queen's Medical Centre, Nottingham NG7 2UH, UK. Email: tim.calton@ btinternet.com

${ }^{\dagger}$ For commentaries on this article see pp. 218-220 and 221-223, this issue. 
rates of recovery (Harrow 2005) and better global functioning (Harrow 2007) than those who remain in the system.

\section{User feedback}

Going further, service users have questioned the emphasis given to medication wedded, as it almost invariably is, to a biomedical framing of their experiences (Rogers 1998). They have complained that side-effects such as loss of motivation, sexual dysfunction, weight gain, drowsiness and restlessness (problems not always prevented by, and often associated with, atypical antipsychotic medication) are more troubling than extrapyramidal side-effects (Day 1997) and have argued that medication can actually impede or prevent healing, learning and recovery (Statsny 2007). Consequently, service users consistently call for alternative treatments that make antipsychotic medication less central and just one of many possible treatment choices (Podvoll 2003; Agar-Jacomb 2006; Gray 2006). These calls have resonated with a growing interest among mental health professionals exploring alternatives to current provision within the context of greater patient choice (Read 2004; Lewis 2005).

\section{New ways of thinking}

Finally, critiques of the philosophical assumptions underpinning the biomedical approach to the treatment of schizophrenia have begun to gain traction. For example, the canonical view of the nature of schizophrenia suggests a disease of the brain (Hyman 1998). Given this assumption, we might suppose that methodological reductionism (Box 1) would be the most useful approach to understanding schizophrenia - seeking to know the disorder through garnering more and more information about the function and dysfunction of affected brains. Indeed, this seems to have been the case throughout the history of modern psychiatry (Griesinger 1868; Pincus 1993; Moncrieff 2001) and, in particular, during the closing decades of the 20th century, a period that witnessed major technological advances in the neurosciences (Calton 2009).

\section{B0X 1 Reductionism}

Methodological reductionism assumes that to understand something you have to render it down to its constituents, then individually scrutinise these (elements, molecules, cells, neural circuits, etc.) and their properties. The idea is that once the constituents have been thoroughly investigated, an understanding can be reached as to how they might interact to create the original system if it were re-formed
However, there are certain problems inherent in this approach. First, attempting to understand a psychological experience solely by studying the brain commits the 'mereological fallacy' (Bennett 2003), that is, the act of ascribing to the constituent parts of a thing attributes that logically apply only to the whole. Hence, attempting to understand the human experience of schizophrenia requires reference to psychological predicates (distress, persecutory thoughts, hallucinations), yet these apply only paradigmatically to the human being as a whole (it is illogical, given our current level of neuroscientific understanding, to talk of a brain hallucinating or feeling distressed). It follows that if the understanding of a human experience such as schizophrenia requires an interest in the whole person, then any attempt to help that person that relies on the use of the above predicates demands a similar approach. However, conventional biomedical treatment for people diagnosed with schizophrenia relies almost entirely on medication designed solely to affect brain function, thereby treating a part of the person and not the whole.

Second, the recent interest in neuroscientific accounts of schizophrenia (Calton 2009), particularly those emanating from functional neuroimaging, appears, at least to some extent, predicated on the assumption that there is something novel or exciting about demonstrating that the brain is involved in human experiences called mental illnesses. We wonder whether this may reflect a deeply sedimented Cartesian dualism wherein mind and body (brain) comprise two different and ineluctably separate substances (Descartes 1637). In this ordering of the world it would be astounding to show that a mental disorder such as schizophrenia can influence the brain (and vice versa). However, most contemporary philosophers of mind would probably draw back from a dualist approach to consciousness, instead preferring to see it as an embodied phenomenon, attendant on, but not exclusive to, the brain (Rose 2006).

\section{A deeper understanding of experience}

In effect, we perhaps should not be so ready to stand in awe of prettily coloured images of brains claiming to represent particular states of mind. Of course the brain is involved in those aspects of conscious experience described as mental illnesses, but it does not follow that this experience can or should be wholly accounted for by reference to brain activity alone. Consequently, it might seem a little misguided to place undue emphasis on treating mental disorders such as schizophrenia by using interventions (such as antipsychotic medication) that are designed solely to alter brain activity. Furthermore, we might imagine that alternative, minimal (or no) medication 
approaches, which perhaps more readily embrace the idea of treating the whole person (and thus neither commit the mereological fallacy nor reduce human experience simply to brain function), could potentially be at least as effective as antipsychotic medication in tending the distress sometimes associated with schizophrenia.

What follows is a review of approaches to treating schizophrenia using no or minimal antipsychotic medication. Owing to our interest in trying to understand the potential efficacy and utility of the whole-person approach, we include only those studies that immersed their participants in a holistic therapeutic milieu. Therefore, we excluded treatment studies that were based solely on psychodynamic or cognitive-behavioural approaches because, like medication, these are arguably designed to influence specific aspects of human consciousness, such as intra-psychic processes or cognitive schema.

\section{Historical evidence from the distant past}

\section{Community care}

Modern psychiatry is but a fragment of the history of madness (Porter 2002). The treatment of schizophrenia with antipsychotic medication is, therefore, a modern phenomenon and one standing atop and alongside other, older traditions of thought and practice. For 700 years people who have experienced what modern psychiatry now terms schizophrenia have lived as members of the community in Geel, a city in Belgium (Goldstein 2003). Prior to (and during) the period in which the use of antipsychotic medication was becoming popular in the West, 'the mad' would be housed with local families; these boarders would be assimilated into the family structure, receiving support and care that allowed them to function in the 'normal' social world despite the emotional distress that some experienced. Research in the modern era suggests that the Geel foster-family approach works because it stands apart from the biomedical model, with its emphasis on diagnosis and treatment using medication (Pierloot 1981).

\section{Self-help}

Likewise, the 'moral treatment' developed at the York Retreat by William Tuke towards the end of the 18th century emanated from outside the ambit of medicine in response to the brutality of contemporaneous treatments (Digby 1985). This non-medical approach encouraged the exercise of residents' self-control rather than punishment, strove for peace, respect and dignity in all relationships, and emphasised the importance of maintaining usual social activities, work and exercise (Warner 1997). Contemporary data suggest that mortality at
The Retreat was low compared with other asylums and its recovery rate of $54.5 \%$ for first admissions also compared favourably (Digby 1985). It may seem strange to discuss such supposedly outmoded traditions of thought and practice in a journal entitled Advances in Psychiatric Treatment, yet we argue that these approaches, predicated as they were on a gentle and humane engagement with the vagaries of human experiences at the limits, and invoking respect, dignity, collective responsibility and an emphasis on interpersonal relationships as guiding principles, retain an immediacy and relevance for the contemporary treatment of schizophrenia.

\section{Evidence from the past 50 years}

\section{The Soteria paradigm}

In the late 1960s and early 1970s, there were a number of attempts to create alternatives to orthodox medication and hospital-based treatment for people diagnosed with schizophrenia (Cooper 1967; Burston 2000). These initiatives cohered around a non-medical understanding of schizophrenia as constituting an important and thoroughly meaningful aspect of an individual's life history. Contrary to the received wisdom of the day, the use of antipsychotic medication was marginalised, with an emphasis instead on enabling individuals to go through their experience of psychosis with minimal interference and high levels of support (Pullen 1999). Relatively well-known UK-based initiatives included Kingsley Hall, associated with R. D. Laing and colleagues (Barnes 1971) and Villa 21, associated with David Cooper (Cooper 1967). These ventures inspired interest at an international level and catalysed the development of similar programmes in other countries. Among these 'second-generation' alternatives was the Soteria paradigm, initially developed by Mosher and colleagues in the USA (Mosher 1999) and then replicated, albeit in a slightly modified form, in Switzerland by Ciompi and colleagues (Ciompi 1992). Several detailed expositions of the paradigm are available (Warner 1997; Mosher 2004a,b; Watkins 2006).

The Soteria paradigm encompasses both theoretical and practical elements that over time have accreted into the 'Soteria critical elements' (Aderhold 2007), which are summarised in Box 2.

At the paradigm's core is the strong assumption that a person diagnosed with schizophrenia should be engaged with at the interpersonal level, with an emphasis on securing shared meanings and understandings of their subjective experience (Mosher 1975). Overarching and all-encompassing theories of disease, professionally acquired belief systems and practices, and the chemical alteration of consciousness by antipsychotic drugs are all considered 
B0X 2 The Soteria critical elements

\begin{tabular}{|c|c|c|}
\hline Facility & Staff & Medications \\
\hline - Small and community-based & - May be mental health professionals, specifically & - No or low-dose antipsychotic drug use \\
\hline - Open, voluntary and home-like & trained and selected non-professionals, & - Benzodiazepines may be used in the short term \\
\hline - Sleeps no more than ten people, including two & former clients (particularly those treated in the & to help restore sleep/wake cycles \\
\hline staff (one man and one woman) & programme) or a combination of all three & Length of stay \\
\hline - $24-48$ hour shifts to allow prolonged intensive & Relationships & - Sufficient time spent in the programme for \\
\hline one-to-one contact & - Staff remain ideologically uncommitted & residents to develop relationships that allow \\
\hline Social structure & - Convey positive expectations of recovery & precipitating events to be acknowledged, and \\
\hline $\begin{array}{l}\text { - Preserves personal power, to preserve autonomy, } \\
\text { diminish the hierarchy in the facility, prevent the } \\
\text { development of unnecessary dependency and } \\
\text { encourage reciprocal relationships }\end{array}$ & $\begin{array}{l}\text {-Validate residents' subjective experience of } \\
\text { psychosis as real by developing an understanding } \\
\text { of it through spending time with and doing } \\
\text { activities with them }\end{array}$ & $\begin{array}{l}\text { painful (and potentially disavowed) emotions to } \\
\text { be experienced, expressed and understood in the } \\
\text { context of the residents' lives } \\
\text { Aftercare }\end{array}$ \\
\hline $\begin{array}{l}\text { - Minimal role differentiation (between staff } \\
\text { and residents) to encourage flexibility of roles, }\end{array}$ & $\begin{array}{l}\text { - Avoid psychiatric jargon in interactions with } \\
\text { residents }\end{array}$ & $\begin{array}{l}\text { Post-discharge relationships encouraged (with } \\
\text { staff and peers) to allow easy return to the }\end{array}$ \\
\hline relationships and responsibilities & Therapy & facility (if necessary) and to foster development \\
\hline $\begin{array}{l}\text { Daily running of the facility is shared as much } \\
\text { as possible. Residents do the cooking, cleaning, }\end{array}$ & $\begin{array}{l}\text { - All activities viewed as potentially therapeutic } \\
\text { but without formal therapy sessions }\end{array}$ & $\begin{array}{l}\text { of peer-based, problem-solving, community- } \\
\text { based social networks }\end{array}$ \\
\hline $\begin{array}{l}\text { shopping, etc. to maintain attachments to } \\
\text { ordinary life }\end{array}$ & $\begin{array}{l}\text { - In-house problems dealt with immediately by } \\
\text { communal problem-solving sessions }\end{array}$ & \\
\hline
\end{tabular}

barriers to this process (Mosher 2004a). To this end the ethos of the original Soteria house repudiated the conventional biomedical approach (and in fact distanced itself from any consistent ideological framework). The treatment facility was a suburban house staffed by non-professionals trained to tend to people at the limits of human experience without succumbing to the usual assumptions and prejudices (Mosher 1973). The facility used contextual constraints to engender a defined and predictable social environment within which so-called interpersonal phenomenology could be practised (Box 3). Finally, and perhaps most importantly for the purposes of this critique, the use of antipsychotic medication was marginalised, and ordinarily such drugs were not prescribed for at least the initial 6 weeks of treatment (Mosher 1975).

All of the above would perhaps be of limited interest to modern psychiatry were it not for the systematic and sustained empirical evaluation of the paradigm's efficacy that has been undertaken over the almost 40 years since its inception (Calton 2008).

\section{Testing the paradigm}

Three randomised controlled trials of the efficacy of the Soteria paradigm have been conducted: two in the USA (Bola 2003) and one in Switzerland (Ciompi 1992). The 223 participants (179 in the USA study, and 44 in the Swiss) were diagnosed with first- or second-episode schizophrenia-spectrum disorders. These studies compared people treated in Soteria communities with people who received treatment as usual (TAU), meaning hospital admission and treatment with antipsychotic medication. These have generated a considerable secondary literature, with 76 citations currently identifiable (Calton 2008). The US trials found that at 6-week followup there were significant and similar improvements in global psychopathology in both the Soteria group and the TAU group, even though only $24 \%$ of the Soteria group had received any antipsychotic

\section{BOX 3 Creating the Soteria environment}

Contextual constraints

- Do no harm

- Treat everyone, and expect to be treated, with dignity and respect

- Guarantee sanctuary, quiet, safety, support, protection, containment and interpersonal validation

- Ensure food and shelter

- Create an atmosphere imbued with hope - recovery from psychosis is expected and is possible without antipsychotic drugs

Interpersonal phenomenology

- Focus on developing a non-intrusive, non-controlling but actively empathic relationship with residents by just spending time with them, without having to do anything explicitly therapeutic or controlling. The aim is to develop a shared experience of the meaningfulness of the resident's individual social context, both current and historical 
medication (and only $16 \%$ of these had received drug treatment for longer than a week). Multivariate analysis of 2-year follow-up data found significantly greater improvements in global psychopathology and 'composite outcome' (an eight-item assessment including employment and social functioning; Bola 2002) significantly more participants living independently, and significantly fewer readmissions for the Soteria group compared with the TAU group (Bola 2003). In addition, only 34\% of the Soteria group had taken antipsychotic medication (continuously or intermittently), compared with $95 \%$ of the TAU group (43\% of the Soteria participants had taken no antipsychotic medication at all). Only 59\% of the Soteria group had received psychiatric treatment, compared with $100 \%$ of those in treatment as usual (Warner 1997).

The Swiss trial reported outcomes on a range of measures, including the Brief Psychiatric Rating Scale, housing and employment status, global outcome, global autonomy, relapse rate and average medication dose (Ciompi 1992). At 2-year followup, TAU and Soteria participants demonstrated similar levels of psychopathology and functioning, with the Soteria group using significantly lower doses of antipsychotic medication (25\% less during the acute treatment phase and 50\% less overall). Both the US and Swiss studies reported longer stays in the Soteria communities than in hospital, but additional costs were offset by the much lower prevalence of antipsychotic use, not to mention the reduced 'personal' costs of not using medication. It must be borne in mind that there is no evidence to suggest that the three iterations of the Soteria paradigm cost more than treatment as usual, and some limited evidence to show that they cost less (Ciompi 2004).

\section{The Finnish collaborative studies}

From 1967, Yrjo Alanen and colleagues in Turku, Finland, developed a primarily psychosocial approach to the care of people diagnosed with early schizophrenia. This need-adapted or integrated approach is fast becoming the standard treatment for schizophrenia in Finland (Mosher 2004a) and is based on several core principles (Alanen 1991), some of which are given in Box 4. It could be argued that this represents a holistic approach to care and, although antipsychotic medication was used, the original model advocated withholding drugs for an initial 3-week assessment period to enable psychosocially informed recovery.

The Acute Psychosis Integrated Treatment Project, which began in 1992, specifically addressed the issue of medication (Lehtinen 2000). It involved six study centres (all of which stuck to the need-adapted
BOX 4 Core principles of the need-adapted approach

- Flexible and individually tailored therapeutic interventions designed to meet the needs of service users and their families, with an emphasis on developing shared understandings of their subjective experiences

- Using a predominantly psychotherapeutic attitude towards examination and treatment, emphasising an attempt to understand what has happened and is happening to the service users and their significant others

- The various therapeutic activities deployed should complement each other. Teamwork, cooperation and good communication are central

- Treatment is considered a work in progress and not an end in itself. Therefore, continuity of care, together with critical thinking and reflexive (recursive) thought, illuminating the circular relationship between cause and effect, are emphasised

model), three of which employed a no or low-dose antipsychotic drug approach after an initial 3-week antipsychotic-free period (experimental group), with the remainder using antipsychotics at recommended therapeutic doses (control group). The study enrolled 106 participants (67 experimental and 39 control - the majority diagnosed with schizophrenia). Whole-cohort analysis after 2 years showed that $41 \%$ had spent less than 2 weeks in hospital over the study period, $52 \%$ had experienced no psychotic symptoms in the previous year and 40\% had Global Assessment Scale (GAS) scores of 70 or more (suggesting relatively good global functioning) (Endicott 1976). Employment data showed that $47 \%$ were working, which is interesting given that US data have suggested that only $15-20 \%$ of people diagnosed with schizophrenia are working 2 years after admission (Mosher 2004a). In the experimental group, $43 \%$ had never taken antipsychotic medication, whereas the corresponding figure for the control group was $6 \%$. The experimental group had received significantly less hospital treatment and had experienced fewer psychotic symptoms during the previous year (Lehtinen 2000).

\section{Further study}

An iteration of the need-adapted approach conducted in Sweden reported results similar to those achieved with treatment as usual, but at about half of the direct economic costs (Cullberg 2002, 2006). Jaakko Seikkula and colleagues in Oulu, Finland, have further refined the need-adapted approach (Mosher 2004a). Their open-dialogue family and network approach (Seikkula 2006) aims to treat people diagnosed with schizophrenia in their own homes. The treatment involves the service user's social network and starts within the first 24 hours of initial contact, with the general aim of generating a constructive dialogue with the person and their family in an effort to find personally meaningful 
understandings of their experiences. People diagnosed with schizophrenia and treated using this version of the need-adapted approach had significantly fewer relapses and residual psychotic symptoms, were more likely to be employed, spent significantly less time in hospital and used antipsychotics significantly less often than people exposed to treatment as usual (Seikkula 2003).

\section{US studies}

From the 1950s until the late 1970s a series of studies concerning the treatment of schizophrenia with or without antipsychotic medication was conducted in the USA (Wirt 1959; Pasamanick 1967; Schooler 1967; Klein 1973; Carpenter 1977; Goldstein 1978; Rappaport 1978; May 1981). Most were placebocontrolled immediate assignment studies that used only antipsychotic medication in their experimental cohorts (and thus did not attempt to treat the whole person). For the purposes of this review only two bear further scrutiny: the studies conducted by William Carpenter and colleagues at the US National Institute of Mental Health in Maryland (Carpenter 1977) and by Maurice Rappaport and colleagues at the St Agnews State Hospital in California (Rappaport 1978). Both are of note because, unlike the others, they used specially designed therapeutic (albeit hospital-based) milieus that emphasised self-understanding, social adaptation, tolerance of bizarre behaviour, interpersonal support and a willingness to give considerable time and attention to a person going through crisis.

In the Carpenter study, 49 people diagnosed with 'good-prognosis schizophrenia', a record of adequate prior work and social functioning, and a short history of illness, were arbitrarily assigned by their psychiatrist to treatment with or without antipsychotic medication (Warner 1997). There were no differences between the two groups with regard to their prognostic ratings and initial clinical characteristics. At 1-year follow-up the people assigned to the no-medication arm spent significantly less time in hospital (108 days compared with 126 days) and were significantly less likely to be readmitted (35\% v. $45 \%)$ or be treated with drugs (44\% v. $67 \%)$ during post-discharge follow-up (Carpenter 1977).

In the Rappaport study, 80 young men with a diagnosis of acute schizophrenia were randomly assigned on admission to either antipsychotic medication or a placebo, with both groups being exposed to the same therapeutic milieu. At 3-year follow-up, 73\% of the medicated group had been readmitted to hospital, compared with $8 \%$ of those originally given a placebo and thereafter never medicated. The authors concluded that 'anti- psychotic medication is not the treatment of choice, at least for certain patients, if one is interested in long-term clinical improvement' (Rappaport 1978). This tradition of research stimulated a long-standing debate concerning the ethics of medication-free research into the treatment of schizophrenia, which continues to this day (Rothman 1994; Carpenter 1997a; Fins 1997; Wyatt 1997; Moser 2005; Bola 2006). The consensus appears to be that such research is not associated with widespread problems of informed consent or adverse consequences to patients and is ethically justifiable in the search for new treatments (Carpenter 1997b; Bola 2009).

\section{Beyond medication, beyond psychiatry and beyond psychosis}

Where would you turn if you went to the limits of human experience, experiencing 'madness' and potentially extreme distress? One of us (T.C.) confronted this question recently when he experienced an episode of what could be called psychosis. What follows is a personal account of certain aspects of that experience. This opening up of experience is intended to provide a personal and thus necessarily subjective perspective on this debate and, in doing so, perhaps return it to its starting point: the particularity of human experience understood in its wider material, historical and social context.

\section{Personal experience: Tim Calton}

The question feels quite easy to answer; I would not engage with psychiatric services and, in fact, would do my best to stay as far away as possible from them. These experiences came about in a particular context and for particular reasons, and I would not want them dishonoured by being forced to understand them as figments of an imagined illness. The one-size-fits-all approach to understanding and treating madness is anathema to me: where is the room for thought about personal crises, the influence of past and current stress, and just different ways of seeing the world in the monolith of psychosis/schizophrenia? Hearing voices did not bother me, though the experience of my thoughts being available to everyone in the room, the lurching inversion of the utterly private into the public, was terrifying beyond belief and led to what I can only describe as a stupor; I was literally paralysed with fear. More insidious was the thought that those people who purported to love and like me were lying, perhaps even plotting against me. It felt like falling off the calendar. I think it speaks volumes about their capacity to tolerate difference, idiosyncrasy, and uncertainty that we were able to find a way through those moments in the abyss together, without recourse to such deadening concepts as 'psychosis' and 'schizophrenia' and certainly without the need for chemical sanitation. That the people who helped in those moments were psychiatrists is an irony not lost on me (or them). That I was very fortunate to be with people with a capacity to tolerate the extreme nature of the situation is something I reflect on (and am grateful for) every day. I think the lack of treatment 
choices for people diagnosed with schizophrenia and/ or experiencing psychosis is abject and shames our profession.

\section{Conclusions}

Even the most conservative analysis of the data presented above would probably concede that it may be possible to treat people diagnosed with first- or second-episode schizophrenia by using psychosocially oriented therapeutic milieux and minimal or no antipsychotic medication at least as effectively, and at no more fiscal cost, than standard care. That said, it is abundantly clear that most of the studies cited included only people diagnosed with early schizophrenia, did not use a randomised controlled methodology (currently regarded as the gold standard for evaluating treatment efficacy in psychiatry), had small numbers of participants and used an ostensibly heterogeneous array of therapeutic milieux. However, this article was never intended to convince the psychiatric profession of the absolute rectitude of our position or argue that these approaches be adopted wholesale. We instead hope to open up a space in which the option of minimal or no medication approaches to treating schizophrenia can be considered and discussed here in the UK. Such openness is necessary in order to support those psychiatrists currently attempting to treat people who do not agree with a medical understanding of their experiences. Given that patient choice will remain an essential component of National Health Service policy (Department of Health 2008), yet is so absent in the treatment of schizophrenia in the UK, and in light of the fact that we are already being left behind by several of our European neighbours with respect to alternative provision, perhaps the time for this discussion is now upon us.

\section{References}

Aderhold V, Statsny P, Lehmann P (2007) Soteria. An alternative mental health reform movement. In Alternatives beyond psychiatry (eds $\mathrm{P}$ Statsny, P Lehmann): 146-60. Peter Lehmann Publishing.

Agar-Jacomb KM (2006) Mental Health Crisis Services. What Do Service Users Need When in Crisis? A Retrospective Study. University of Auckland.

Alanen Y0, Lehtinen K, Räkköläinen V, et al (1991) Need-adapted treatment of new schizophrenic patients. Experiences and results of the Turku Project. Acta Psychiatrica Scandinavica; 83: 363-72.

Barnes M, Berke J (1971) Mary Barnes. Two Accounts of a Journey through Madness. MacGibbon and Kee.

Bennett MR, Hacker PMS (2003) Philosophical Foundations of Neuroscience. Blackwell.

Bentall RP, Morrison AP (2002) More harm than good. The case against using antipsychotic drugs to prevent severe mental illness. Journal of Mental Health; 11: 351-6.

Bola JR, Mosher LR (2002) Predicting drug-free treatment response in acute psychosis from the Soteria Project. Schizophrenia Bulletin; 28: 559-75.
Bola JR, Mosher LR (2003) Treatment of acute psychosis without neuroleptics. Two-year outcomes from the Soteria Project. Journal of Nervous and Mental Disease; 191: 219-29.

Bola JR (2006) Medication-free research in early episode schizophrenia. Evidence of long-term harm? Schizophrenia Bulletin; 32: 288-96.

JR Bola, Lehtinen, K, Cullberg, J, et al (2009) Psychosocial treatment, antipsychotic postponement, and low-dose medication strategies in first-episode psychosis: a review of the literature. Psychosis; 1 : 4-18.

Burston D (2000) The Crucible of Experience: R.D. Laing and the Crisis of Psychotherapy. Harvard University Press.

Calton T, Ferriter M, Huband N, et al (2008) A systematic review of the Soteria paradigm for the treatment of people diagnosed with schizophrenia. Schizophrenia Bulletin; 34: 181-92.

Calton T, Cheetham A, D'Silva K, et al (2009) International schizophrenia research and the concept of patient-centredness: an analysis over two decades. International Journal of Social Psychiatry, 55: 157-69.

Carpenter WT, McGlashan TH, Strauss JS (1977) The treatment of acute schizophrenia without drugs. An investigation of some current assumptions. American Journal of Psychiatry, 134: 14-20.

Carpenter WT (1997a) The risk of medication-free research. Schizophrenia Bulletin; 23: 11-8.

Carpenter WT, Schooler NR, Kane JM (1997b) The rationale and ethics of medication-free research in schizophrenia. Archives of General Psychiatry, 54: 401-7.

Ciompi L, Dauwalder HP, Maier C, et al (1992) The pilot project 'Soteria Berne'. Clinical experiences and results. British Journal of Psychiatry, 161 (suppl 18): 145-53.

Ciompi L, Hoffmann H (2004) Soteria Berne. An innovative milieu therapeutic approach to acute schizophrenia based on the concept of affect-logic. World Psychiatry, 3: 140-6.

Cooper D (1967) Psychiatry and Anti-psychiatry. Tavistock Press.

Cullberg J, Levander S, Holmqvist R, et al (2002) One-year outcome in first episode psychosis patients in the Swedish Parachute project. Acta Psychiatrica Scandinavica; 106: 276-85.

Cullberg J, Mattsson S, Levander R, et al (2006) Treatment costs and clinical outcomes for first episode schizophrenia patients. A 3-year follow-up of the Swedish 'Parachute Project' and two comparison groups. Acta Psychiatrica Scandinavica; 114: 274-81.

Davis JM (1976) Recent developments in the drug treatment of schizophrenia. American Journal of Psychiatry, 133: 208-14.

Davis JM, Chen N, Glick ID (2003) A meta-analysis of the efficacy of second-generation antipsychotics. Archives of General Psychiatry, 60: 553-64.

Day J, Kinderman P, Bentall R (1997) A comparison of patients' and prescribers' beliefs about neuroleptic side-effects: prevalence, distress and causation. Acta Psychiatrica Scandinavica; 97: 93-7.

Department of Health (1999) National Service Framework for Mental Health. Department of Health.

Department of Health (2003) Building on the Best. Choice, Responsiveness and Equity in the NHS. Department of Health.

Department of Health (2008) High Quality Care for All. Department of Health.

Descartes R (1637) Discours de la méthode pour bien conduire sa raison, et chercher la verité dans les sciences. Reprinted (2006) as A Discourse on the Method (trans I Maclean). Oxford University Press.

Digby A (1985) Madness, Morality and Medicine. A Study of the York Retreat, 1796-1914. Cambridge University Press.

Endicott J, Spitzer RL, Fleiss JL, et al (1976) The Global Assessment Scale. A procedure for measuring overall severity of psychiatric disturbance. Archives of General Psychiatry, 33: 766-71.

Fins JJ, Miller FG (1997) The call of the sirens. Navigating the ethics of medication-free research in schizophrenia. Archives of General Psychiatry, 54: 415-6. 


\begin{tabular}{lllll}
\multicolumn{5}{l}{ MCO } \\
1 & 2 & 3 & 4 & 5 \\
af & af & af & af & at \\
bf & bf & bf & bf & bf \\
cf & ct & cf & cf & cf \\
df & df & dt & dt & df \\
et & ef & ef & ef & ef
\end{tabular}

Fulford KWM (1996) Concepts of disease and the meaning of patientcentred care. In Essential Practice in Patient-centred Care (ed KWM Fulford, T Hope): 3-4. Blackwell Science.

General Medical Council (1998) Seeking Patients' Consent. The Ethical Considerations. General Medical Council.

Goldstein MJ, Rodnick EH, Evans JR, et al (1978) Drug and family therapy in the aftercare of acute schizophrenics. Archives of General Psychiatry, 35: 1169-77.

Goldstein JL, Godemont MML (2003) The legend and lessons of Geel, Belgium. A 1500-year-old legend, a 21st-century model. Community Mental Health Journal; 39: 441-58.

Gray P (2006) The Madness of Our Lives. Experiences of Mental Breakdown and Recovery. Jessica Kingsley.

Griesinger W (1868) Vorwort. Archiv für Psychiatrie und Nervenkrankheiten; 1: 3

Grisso T, Appelbaum PS (1995) Comparison of standards for assessing patients' capacities to make treatment decisions. American Journal of Psychiatry, 152: 1033-7.

Harrow M, Grossman L, Jobe T, et al (2005) Do patients with schizophrenia ever show periods of recovery? A 15-year multi-follow-up study. Schizophrenia Bulletin; 31: 723-34.

Harrow M, Jobe TH (2007) Factors involved in outcome and recovery in schizophrenia patients not on antipsychotic medications. A 15-year multifollow-up study. Journal of Nervous and Mental Disease; 195 : $406-14$

Hennessy S, Bilker WB, Knauss JS, et al (2002) Cardiac arrest and ventricular arrhythmia in patients taking antipsychotic drugs. Cohort study using administrative data. BMJ; 325: 1070-2

Hogarty GE, Goldberg SC, Schooler S, et al (1974) Drug and sociotherapy in the aftercare of schizophrenic patients II. Two year relapse rates. Archives of General Psychiatry, 31: 603-8.

Hope T (2002) Evidence-based patient choice and psychiatry. EvidenceBased Mental Health; 5: 100-1

Hyman SE, Lieberman J, Weinberger DR (1998) Schizophrenia. Understanding It, Treating It, Living with It. Library of Congress.

Jones PB, Barnes TRE, Davies L, et al (2006) Randomized controlled trial of the effect on quality of life of second- vs first-generation antipsychotic drugs in schizophrenia. Archives of General Psychiatry, 63: 1079-87.

Kane J, Meltzer H, Carson W, et al (2007) Aripiprazole for treatmentresistant schizophrenia. Results of a multicenter, randomized, doubleblind, comparison study versus perphenazine. Journal of Clinical Psychiatry, 68: 213-23.

Klein DF, Rosen B (1973) Premorbid asocial adjustment and response to phenothiazine treatment among schizophrenic inpatients. Archives of General Psychiatry, 29: 480-5.

Lehtinen V, Aaltonen J, Koffert T, et al (2000) Two-year outcome in firstepisode psychosis treated according to an integrated model. Is immediate neuroleptisation always needed? European Psychiatry, 15: 312-20.

Lewis SW, Tarrier N, Drake, RJ (2005) Integrating non-drug treatments in early schizophrenia. British Journal of Psychiatry, 187: 65-71.

Lieberman JA, Scott Stroup, T, McEvoy, JP, et al (2005) Effectiveness of antipsychotic drugs in patients with chronic schizophrenia. New England Journal of Medicine; 353: 1209-23.

Loebel AD, Lieberman JA, Alvir JM, et al (1992) Duration of psychosis and outcome in first-episode schizophrenia. American Journal of Psychiatry, 149: 1183-8.

May PRA, Tuma AH, Dixon WJ, et al (1981) Schizophrenia: a followup study of the results of five forms of treatment. Archives of General Psychiatry, 38: 776-84.

Moncrieff J, Crawford MJ (2001) British Psychiatry in the 20th century. Observations from a psychiatric journal. Social Science and Medicine; 53: $349-56$

Moncrieff J (2003) Clozapine v. conventional antipsychotic drugs for treatment-resistant schizophrenia: a re-examination. British Journal of Psychiatry, 183: 161-6.
Moser DJ, Reese RL, Schultz SK, et al (2005) Informed consent in medication-free schizophrenia research. American Journal of Psychiatry, 162: $1209-11$.

Mosher LR, Reifman A, Menn, A (1973) Characteristics of nonprofessionals serving as primary therapists for acute schizophrenics. Hospital and Community Psychiatry, 24: 391-6.

Mosher LR, Menn A, Matthew SM (1975) Soteria. Evaluation of a homebased treatment for schizophrenia. American Journal of Orthopsychiatry, 45: 455-67.

Mosher LR (1999) Soteria and other alternatives to acute psychiatric hospitalization. A personal and professional review. Journal of Nervous and Mental Disease; 187: 142-9.

Mosher LR (2004a) Non-hospital, non-drug interventions with firstepisode psychosis. In Models of Madness. Psychological, Social and Biological Approaches to Schizophrenia (eds J Read, LR Mosher, R Bentall): 349-64. Brunner-Routledge.

Mosher LR, Hendrix V (2004b) Soteria. Through Madness to Deliverance. XLibris.

National Institute for Clinical Excellence (2002) Clinical Guideline 1. Schizophrenia: Core Interventions in the Treatment and Management of Schizophrenia in Primary and Secondary Care. NICE.

Oehl M, Hummer M, Fleischhacker WW (2000) Compliance with antipsychotic treatment. Acta Psychiatrica Scandinavica; 102: 83-6.

Pasamanick B, Scarpetti FR, Dinitz S (1967) Schizophrenics in the Community. An Experimental Study in the Prevention of Rehospitalization. Appleton-Century-Crofts.

Pierloot RA, Demarsin M (1981) Family care versus hospital stay for chronic psychiatric patients. International Journal of Social Psychiatry, 27: 217-24.

Pincus HA, Henderson B, Blackwood D, et al (1993) Trends in research in two general psychiatric journals in 1969-1990. Research on research. American Journal of Psychiatry, 150: 135-42.

Podvoll EM (2003) Recovering Sanity. A Compassionate Approach to Understanding and Treating Psychosis. Shambhala.

Porter R (2002) Madness. A Brief History. Oxford University Press.

Pullen G (1999) Schizophrenia. Hospital communities for the severely disturbed. In Therapeutic Communities. Past, Present and Future leds P Campling, R Haigh): 140-50. Jessica Kingsley.

Rappaport M, Hopkins HK, Hall K, et al (1978) Are there schizophrenics for whom drugs may be unnecessary or contraindicated? International Pharmacopsychiatry, 13: 100-11.

Read J, Mosher L, Bentall R (2004) Models of Madness. Psychological, Social and Biological Approaches to Schizophrenia. BrunnerRoutledge.

Rogers A, Day JC, Williams B, et al (1998) The meaning and management of neuroleptic medication. A study of patients with a diagnosis of schizophrenia. Social Science and Medicine; 47: 1313-23.

Rose D (2006) Consciousness. Philsophical, Psychological, and Neural Theories. Oxford University Press.

Rothman KJ, Michels KB (1994) The continuing unethical use of placebo controls. New England Journal of Medicine; 331: 394-8.

Schooler NR, Goldberg SC, Boothe H, et al (1967) One year after discharge. Community adjustment of schizophrenic patients. American Journal of Psychiatry, 123: 986-95.

Seikkula J, Aaltonen J, Rasinkangas A, et al (2003) Open dialogue approach. Treatment principles and preliminary results of a two-year follow-up on first episode schizophrenia. Ethical and Human Sciences and Services; 5: 163-82

Seikkula J, Aaltonen J, Alakare B, et al (2006) Five-year experience of first-episode nonaffective psychosis in open-dialogue approach. Treatment principles, follow-up outcomes, and two case studies. Psychotherapy Research; 16: 214-28.

Statsny P, Lehmann, P (2007) Alternatives Beyond Psychiatry. Peter Lehmann Publishing.

Warner R (1997) Recovery from Schizophrenia. Psychiatry and Political Economy. Routledge. 
Watkins J (2006) Healing Schizophrenia. Using Medication Wisely. Michelle Anderson.

Wirt RD, Simon W (1959) Differential Treatment and Prognosis in Schizophrenia. Charles C Thomas.
Wyatt RJ (1997) Research in schizophrenia and the discontinuation of antipsychotic medications. Schizophrenia Bulletin; 23: 3-9.

Zarate CA, Patel J (2001) Sudden cardiac death and antipsychotic drugs. Do we know enough? Archives of General Psychiatry, 58: 1168-71.
MCQs

1 The following was or is a UK-based no- or minimal-medication approach to treating schizophrenia:

a the Soteria paradigm

b the Geel 'family boarding' system

c need-adapted treatment

$\mathrm{d}$ the open-dialogue approach

e Villa 21.

2 The social-structure element of the Soteria paradigm includes:

a a clearly defined hierarchy

b daily activities defined and controlled by staff

c curtailment of personal power and autonomy

$\mathrm{d}$ at least weekly contact with medical staff

e minimal rules and structures imposed.
3 Features of a Soteria environment include:

a submission to medical authority

b expectation of recovery from schizophrenia but only with the use of antipsychotic medication

c reducing the residents' ability to influence their immediate environment

d treating everyone with dignity and respect

e employing a token economy to maintain order.

4 Interpersonal phenomenology involves:

a rigid adherence to psychodynamic principles

b avoiding discussing the subjective reality of a person's psychotic experiences

c reference to cognitive-behavioural theory

d 'being with' not 'doing to' (the person in distress)

e playing down the importance of a client's individual social context.
5 Need-adapted treatment includes the following core principle:

a developing shared understandings of the subjective experience of the service user

b using a predominantly biomedical approach to examination and treatment

c employing a disparate array of therapeutic activities, which do not necessarily complement each other

d diagnosis and treatment are ends in themselves

e the involvement of the family is of marginal interest. 